\title{
sciendo
}

\section{CONTAMINATION OF ACORNS OF PEDUNCULATE OAK (QUERCUS ROBUR L.), AS FEED MATERIAL, BY MOULDS AND MYCOTOXINS*}

\author{
Robert Kosicki ${ }^{1 \star}$, Magdalena Twarużek ${ }^{1}$, Krystyna Kannenberg $^{2}$, Jan Grajewski ${ }^{1}$ \\ ${ }^{1}$ Department of Physiology and Toxicology, Faculty of Biological Sciences, \\ Kazimierz Wielki University, Chodkiewicza 30, 85-064 Bydgoszcz, Poland \\ ${ }^{2}$ High School of Environment Management, Pocztowa 13, 89-500 Tuchola, Poland \\ •Corresponding author: robkos@ukw.edu.pl
}

\begin{abstract}
In the past, pigs were commonly fed with acorns, and this was of remarkable economic importance. Currently this habit is continued in some areas, especially for production of prime-quality Iberian ham. Mature acorns, after shedding and during storage in unsuitable conditions, can be quickly infected with spores of many moulds, which cause mummification, blackening, dehydration, and nutrient loss. This study aimed to evaluate the quality of acorns of pedunculate oak (Quercus robur L.). The samples were collected in 2017 in southern Wielkopolska (central part of Poland), as feed material. In mouldy acorns a very high number of fungi was found $\left(2.6 \times 10^{6} \mathrm{cfu} / \mathrm{g}\right)$, and $97 \%$ of them represented pathogenic Penicillium spp. Liquid chromatography-tandem mass spectrometry (LC-MS/MS) analysis showed in mouldy acorns high concentrations of mycophenolic acid $(14580 \mu \mathrm{g} / \mathrm{kg})$ and patulin $(50 \mu \mathrm{g} / \mathrm{kg})$. The dominant mould species, Penicillium expansum, showed a high cytotoxicity of swine kidney cells using assay based on the conversion of the tetrazolium salt, 3-(4,5, dimethylthiazol-2-yl)-2-5 diphenyltetrazolium (MTT). This raises the question if the pathogenic metabolites of moulds present in acorns can be dangerous for livestock, especially pigs, and people, as acorns are beginning to be seen as an interesting and functional part of their diet.
\end{abstract}

Key words: acorns, Quercus robur L., moulds, mycotoxins, liquid chromatography, tandem mass spectrometry, MTT assay

Oaks and their seeds (acorns) have always been of economic, aesthetic, and culture-forming importance. Krahl-Urban (1959) has discussed this issue in historical terms. In ancient Greece, oak trees were devoted to Zeus, whereas the Celtic god of thunder (Taranis) was the protector of oaks. Oak wood has been used by sculptors and oak trees have been common painting themes for ages. Oak forests were planted as hunting grounds. They provide wild animals with rich food reserves for autumn

*This study was supported by the Polish Minister of Science and Higher Education, under the program "Regional Initiative of Excellence" in 2019-2022 (Grant No.008/RID/2018/19). 
and winter, especially in mast seeding years (i.e. when acorn crops are high). However, for a long time acorns were fed to the livestock, especially pigs. This habit is still continued in some European countries, e.g. Spain and Portugal.

Table 1. Nutrient content of stored unshelled acorns and grain of feed cereals

\begin{tabular}{l|c|c|c|c|c}
\hline \multirow{2}{*}{$\begin{array}{c}\text { Nutrient } \\
\text { (g/kg } \\
\text { fresh weight) }\end{array}$} & \multicolumn{5}{c}{ Feed material } \\
\cline { 2 - 6 } & $\begin{array}{c}\text { shelled acorns } \\
\text { (DLG, 1982; } \\
\text { Rakić et al., 2006) }\end{array}$ & $\begin{array}{c}\text { rye } \\
\text { (Feedinamics, } \\
2020)\end{array}$ & $\begin{array}{c}\text { barley } \\
\text { (Feedinamics, } \\
2020)\end{array}$ & $\begin{array}{c}\text { wheat } \\
\text { (Feedinamics, } \\
2020)\end{array}$ & $\begin{array}{c}\text { maize } \\
\text { (Feedinamics, } \\
2020)\end{array}$ \\
\hline Dry matter & 855 & 867 & 872 & 869 & 863 \\
Crude protein & 68 & 85 & 99 & 110 & 76 \\
Crude fibre & 101 & 20 & 47 & 24 & 23 \\
Crude fat & 40 & 12 & 16 & 14 & 36 \\
Crude ash & 22 & 18 & 22 & 15 & 12 \\
Starch & 603 & 537 & 523 & 600 & 638 \\
Sugar & 60 & 31 & 22 & 26 & 17 \\
Lys & 4.1 & 3.4 & 3.7 & 3.2 & 2.3 \\
Met + Cys & 0.9 (Met) & 3.3 & 3.9 & 4.5 & 3.5 \\
Trp & 0.8 & 0.8 & 1.2 & 1.3 & 0.5 \\
Ca & 1.0 & 0.6 & 0.7 & 0.6 & 0.4 \\
P & 1.0 & 3.0 & 3.4 & 3.1 & 2.5 \\
Na & 0.3 & 0.03 & 0.1 & 0.05 & 0.03 \\
Mg & 0.4 & 1.1 & 1.1 & 1.0 & 1.0 \\
K & 8.3 & 4.5 & 4.8 & 3.9 & 3.1 \\
Cl & 0.4 & 0.6 & 1.0 & 0.8 & 0.5 \\
\hline & & & & & \\
\hline
\end{tabular}

Table 1 compares the nutrient content of acorns and major feed materials. Acorns are not suitable for fast-growing meat breeds, because of the lower total protein content, with a shortage of sulphur-containing amino acids. When using unshelled acorns in daily diets of pigs, it must be remembered that this feed material has a high raw fibre content, which may reduce daily weight gain and feed intake (Kamphues et al., 2004). The higher fat, starch, and sugar content of acorns and their high abundance in autumn and winter are utilized for production of prime-quality Iberian ham, known as pata negra. The dark pure Iberian pig breed is kept in large fenced areas with planted cork oaks (Quercus suber L.) or holm oaks (Quercus ilex L.). After shedding of acorns, their contribution to the daily diet increases. This period is called montanera, and is followed by slaughter at the age of more than 14 months (Ortiz et al., 2020). Thanks to the acorn-rich diet, the pork has a nut flavour, and the fat tissue is rich in omega-3 fatty acids and oleic acid. Simultaneously, when pigs are kept in open pastures, muscles produce much more myoglobulin, which results in 
their darker, more saturated in red, meat colour as well as significant meat marbling, similar to that of wild pigs. The fallen acorns in autumn and winter are an important component of the daily food intake for the Iberian pigs kept in pasture. In pig farms, it is necessary to provide appropriate amounts of nutrients. Acorns have an optimum calcium to phosphorus ratio. Their potassium content is excessive, in comparison to sodium, but the shortage of sodium can be easily supplemented with $\mathrm{NaCl}$. Mature acorns contain high concentrations of group $\mathrm{B}$ vitamins (especially $\mathrm{B}_{6}$ and $\mathrm{B}_{9}$ ), and no gluten (DLG, 1982).

In recent years, acorns have been gaining interest as potential component in human nutrition, e.g. as nuts (they resemble chestnuts), as flour (due to high starch contents), or as cooking oil (which presents high similarity with olive oil). Currently acorns are still used for coffee substitute production (Pignone and Laghetti, 2010) and quite popular as a flour for humans, especially those with celiac disease or other types of food intolerances. Mixing acorn and wheat flour can have beneficial rheological effects as adding small amounts of acorn flour will increase the volume of the bread and improve the properties of the crumb (Korus et al., 2015). Oil from acorns (oil content of white species of Quercus reaches 12\%) has good nutritional properties and its taste is similar to olive oil (Özcan, 2007). Charef et al. (2008) also reported that the fatty acid composition of acorn oil from $Q$. suber and $Q$. ilex is similar to that of edible vegetable oils such as those obtained from sunflower, peanut, olive and avocado. Acorns contain aliphatic alcohols (e.g. tetracosanol), which can be used in industry as emulsifiers, emollients and thickeners in food and personal care products (Rabhi et al., 2016). Acorns also contain phenolic compounds (over 60 have been identified so far, e.g. ellagic acid, gallic acid derivatives and several flavonoids) which provide health benefits, which are mainly correlated to their high antioxidant activity. In addition, they play important roles in reducing the risk of cardiovascular and inflammatory diseases, diabetes, cancer, microbial infections, human immunodeficiency virus (HIV) infection, and other diseases (Jiang and Dusting, 2003; Lee et al., 2005; Ullah and Khan, 2008).

Little is known about the problem of acorn contamination with moulds and their secondary metabolites - mycotoxins - and their toxicity to animals that consume large amounts of acorns. The fungus Ciboria batschiana (Zopf) Buchwald (Ascomycota, order Helotiales) causes acorn mummification, commonly known as black acorn rot (Schröder et al., 1999). Acorns are usually infected with spores of this fungus after shedding but occasionally infection takes place on the tree, from fruit bodies growing on mummified seeds. Kozłowska (1970) found that on dead seeds, also the fungus Schizophyllum commune FR develops, which causes brown rot and often spreads to live acorns, causing their death during storage. White rot is due to fungi of the genus Cylindrocarpon (Mańka, 1998). Acorns are often also infected with many other fungi, especially during longer storage in the forest litter or soil. Its symptoms include spots of mycelium on the surface of the seed coat or red aggregations of spores, mostly in spring. Before storage, acorns with symptoms of infection can be removed and destroyed, but we do not know the proportion of mouldy acorns eaten by wild animals. During acorn storage, some fungal species from field conditions are later dominated by storage moulds, and the latter are often able to produce 
toxins (secondary metabolites). In particular, moulds of the genus Penicillium at higher temperatures and humidity are activated on seeds, forming greyish mould. Many fungi of this genus and their metabolites are characterized by high resistance, as they are not affected by high temperature (Przybył, 2006). Little attention has been paid so far to the toxicity of Penicillium spp. on acorns. Mould on acorns can be also formed by fungi of the genera Mucor, Rhizopus, Absidia, Trichothecium or Mortierella, especially at low temperatures, excessive moisture, and in weaker seeds. Additionally, it must be remembered that acorns are commonly colonized by other fungi, too, e.g. by Fusarium or Rhizoctonia spp., which can synthesize toxic metabolites, dangerous for animals (Przybył, 1999). When using acorns as animal feed, it must be remembered that they can contain natural toxins, e.g. phytotoxins and mycotoxins.

Many factors affect fungal development and mycotoxin production. One fungus can produce various mycotoxins and one mycotoxin can be produced by various moulds. Secondary metabolites of moulds have a broad range of mechanisms of activity and toxic effects (from chronic contamination to acute poisoning) and that is why feed materials are often contaminated with several mycotoxins, which is known as multicontamination. Toxicity varies between mycotoxins, and also sensitivity to mycotoxins depends on the time of exposure, dose, species, and phase of physiological development. Plant cells, similarly to moulds, have primary metabolism, which is life-sustaining. However, some plant species and moulds produce a given secondary metabolite in a process during which they produce numerous chemical substances. Many of them are strongly toxic, so they are also used pharmacologically. Major groups of secondary metabolites are e.g. mycotoxins in fungi and tannins in oaks.

In the food chain most of plant toxins are less stable and are subject to additional biotransformation (Dingermann et al., 2012). Their derivatives can be detected in some organs or body fluids (bile or milk). The aim of the presented study was to evaluate the quality of acorns of pedunculate oak (Quercus robur L.) collected in southern Wielkopolska, after storage, in respect of composition and number of colony-forming units of moulds, their cytotoxicity level, and mycotoxin content.

\section{Material and methods}

Acorns were collected in the autumn of 2017 in Czerniejewo Forest District (Poland). The collected acorns were washed with water, subjected to thermotherapy with humid air $\left(41^{\circ} \mathrm{C}, 2 \mathrm{~h}\right)$, dried and stored in plastic barrels with a ventilation chimney for 6 months at $-3^{\circ} \mathrm{C}$. Then, all samples were ground using a Retsch (Haan, Germany) ZM 200 laboratory mill, and stored in plastic bags at $-20^{\circ} \mathrm{C}$ until analysis. On the basis of visual examination they were divided into 2 groups: mould-free (control) and visually infected with moulds (Figure 1). From each group, 15 samples were randomly selected. 

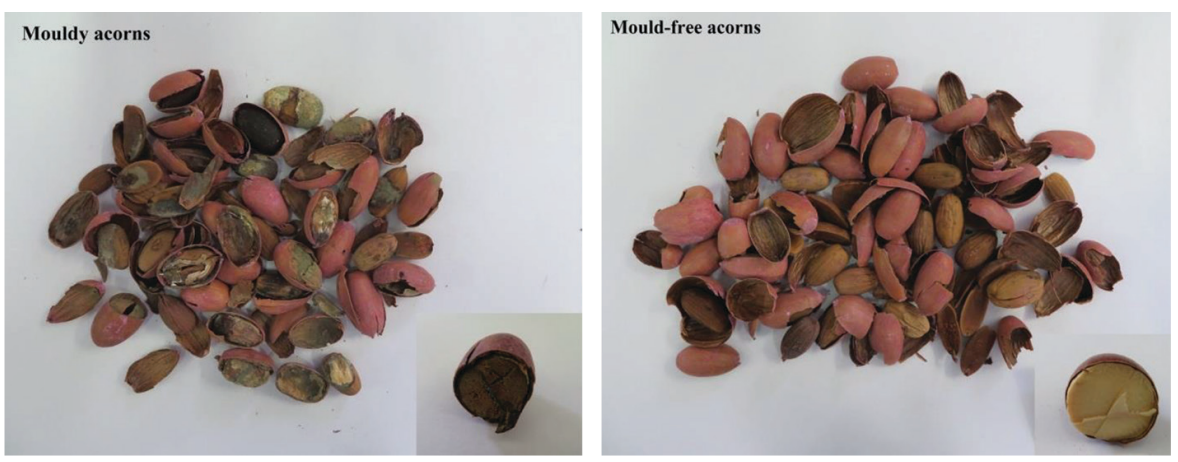

Figure 1. Material used in this study: mouldy and visually mould-free acorns

\section{Mycological examination}

Mould-free acorns (control) and mouldy ones were cut into small, about 5-mm pieces with a sterile scalpel under the laminar chamber. Acorn fragments were plated on YGC agar medium composed of yeast extract and glucose with 100 ppm chloramphenicol, $\mathrm{pH}$ 6.6. The dishes were incubated at $25^{\circ} \mathrm{C}$ for 5 days. Initial identification of moulds was carried out on the basis of colony morphology, sporulation type, and microscopic preparations in lactophenol according to Amann (dyes for testing according to PN-R-64791: 1994). Isolated strains were plated on identification agar media (Czapek yeast extract $\mathrm{CYA} / 25^{\circ} \mathrm{C}, \mathrm{CYA} / 5^{\circ} \mathrm{C}, \mathrm{CYA} / 37^{\circ} \mathrm{C}$, malt extract agar $\mathrm{MEA} / 25^{\circ} \mathrm{C}$, creatine agar $\mathrm{CREA} / 25^{\circ} \mathrm{C}$, yeast extract agar $\mathrm{YES} / 25^{\circ} \mathrm{C}$ ). After incubation for at least 7 days, the strains were identified using the keys by Fassatiova (1983), Samson et al. (2010), Samson and Frisvad (2004 a), Pitt (2000), and Pitt and Hocking (1999).

Quantitative and qualitative assessment of filamentous fungi in acorn samples was performed by a culture method (Koch's decimal dilutions method) using the YGC medium: $100 \mu \mathrm{L}$ were spread on agar medium in 90-mm Petri dishes in triplicate and incubated at $25^{\circ} \mathrm{C}$ for $5-7$ days. The results are expressed as the number of colony-forming units (cfu) per gram of a sample.

\section{Cytotoxicity evaluation}

Cytotoxicity of mould isolates on swine cells was evaluated using assay based on the ability of mitochondrial dehydrogenase to transform a yellow tetrazole soluble in water, namely 3-(4,5-dimethylthiazol-2-yl)-2,5-diphenyltetrazolium bromide (MTT), to insoluble formazan, which is purple. After dissolving the formazan crystals in dimethyl sulfoxide (DMSO), the resultant coloured solution is subjected to spectrometry at a wavelength of $510 \mathrm{~nm}$. The amount of reduced coloured MTT is proportional to the number of metabolically active (live) cells in the population. Cytotoxicity of a given substance is measured as half-maximal inhibitory concentration (IC50), reflecting how much of the substance is needed to reduce cell growth and proliferation to 50\%, as compared to control cells (Hanelt et al., 1994). 


\section{Mycotoxicological analysis}

Each sample $(5 \mathrm{~g})$ was homogenized with $20 \mathrm{ml}$ of a mixture of acetonitrile: water: acetic acid (79:20:1) for 3 minutes. Raw extracts were diluted with the same amount of water, mixed, centrifuged, and injected into the liquid chromatography, tandem mass spectrometry (LC-MS/MS) system. Detection of mycotoxins was carried out using high-performance liquid chromatograph (HPLC) Nexera (Shimadzu, Tokyo, Japan) with a mass detector API 4000 (Sciex, Foster City, USA). Mycotoxins were separated on a chromatographic column Gemini NX-C18 $(150 \times 4.6 \mathrm{~mm}, 3 \mu \mathrm{m})$ (Phenomenex, Torrance, CA, USA). The flow rate was $0.75 \mathrm{ml} / \mathrm{min}$ and the injection volume was $7 \mu \mathrm{l}$. Mobile phases were: $\mathrm{A}=1 \% \mathrm{AcOH}$ in water and $\mathrm{B}=1 \% \mathrm{AcOH}$ in methanol (both phases contained $5 \mathrm{mmol} / \mathrm{L}$ ammonium acetate) with the following gradient: $10 \% \mathrm{~B}$ up to $2.0 \mathrm{~min}, 97 \% \mathrm{~B}$ from 2.0 to $14.0 \mathrm{~min}, 97 \% \mathrm{~B}$ up to $16.0 \mathrm{~min}$, then $10 \%$ B. Sample preparation and HPLC analysis of mycotoxins were performed by the technique described by Viegas et al. (2019).

\section{Results}

\section{Mycological examination}

The total number of fungi (cfu/g) was estimated at $1.0 \times 10^{4}$ and $2.6 \times 10^{6}$ in mould-free and mouldy acorns, respectively. The acorn samples were dominated by moulds of the genus Penicillium (97\%). Table 2 presents the results of mycological analysis of randomly selected acorns on YGC medium. The most frequently isolated fungi from acorns were: Penicillium paneum, Penicillium crustosum, Penicillium aurantiogriseum, Penicillium expansum, Trichoderma sp., Mucor circinelloides, Mucor hiemalis, Alternaria alternate, and Fusarium solani.

Table 2. The main moulds of the genus Penicillium presented in contaminated acorns

\begin{tabular}{|c|c|}
\hline Sample no. & Moulds \\
\hline 1 & Penicillium paneum, Mucor hiemalis \\
\hline 2 & Penicillium crustosum, Mucor hiemalis \\
\hline 3 & Penicillium aurantiogriseum, Mucor hiemalis \\
\hline 4 & Penicillium expansum, Mucor hiemalis \\
\hline 5 & Penicillium crustosum, Mucor hiemalis \\
\hline 6 & Penicillium expansum, Mucor circinelloides, Trichoderma $\mathrm{sp}$. \\
\hline 7 & Penicillium paneum \\
\hline 8 & Penicillium paneum, Mucor hiemalis \\
\hline 9 & Penicillium paneum \\
\hline 10 & Penicillium expansum, Mucor circinelloides \\
\hline 11 & Penicillium paneum, Mucor hiemalis \\
\hline 12 & Penicillium expansum, Mucor hiemalis \\
\hline 13 & Penicillium crustosum, Mucor hiemalis \\
\hline 14 & Penicillium aurantiogriseum, Alternaria alternata \\
\hline 15 & Penicillium expansum, Mucor circinelloides, Fusarium solani, Trichoderma sp. \\
\hline
\end{tabular}




\section{Cytotoxicity evaluation}

Cytotoxicity of the most frequently isolated 3 mould species (Penicillium spp.) was evaluated using MTT assay with swine kidney cells (Figure 2), sensitive to a broad range of toxins. The control was Czapek medium. The MTT assay showed that the most cytotoxic species was Penicillium expansum (IC50 $0.061 \mathrm{~cm}^{2} / \mathrm{ml}$ ), followed by P. crustosum (IC50 $7.813 \mathrm{~cm}^{2} / \mathrm{ml}$ ), and P. paneum (IC50 $7.813 \mathrm{~cm}^{2} / \mathrm{ml}$ ).

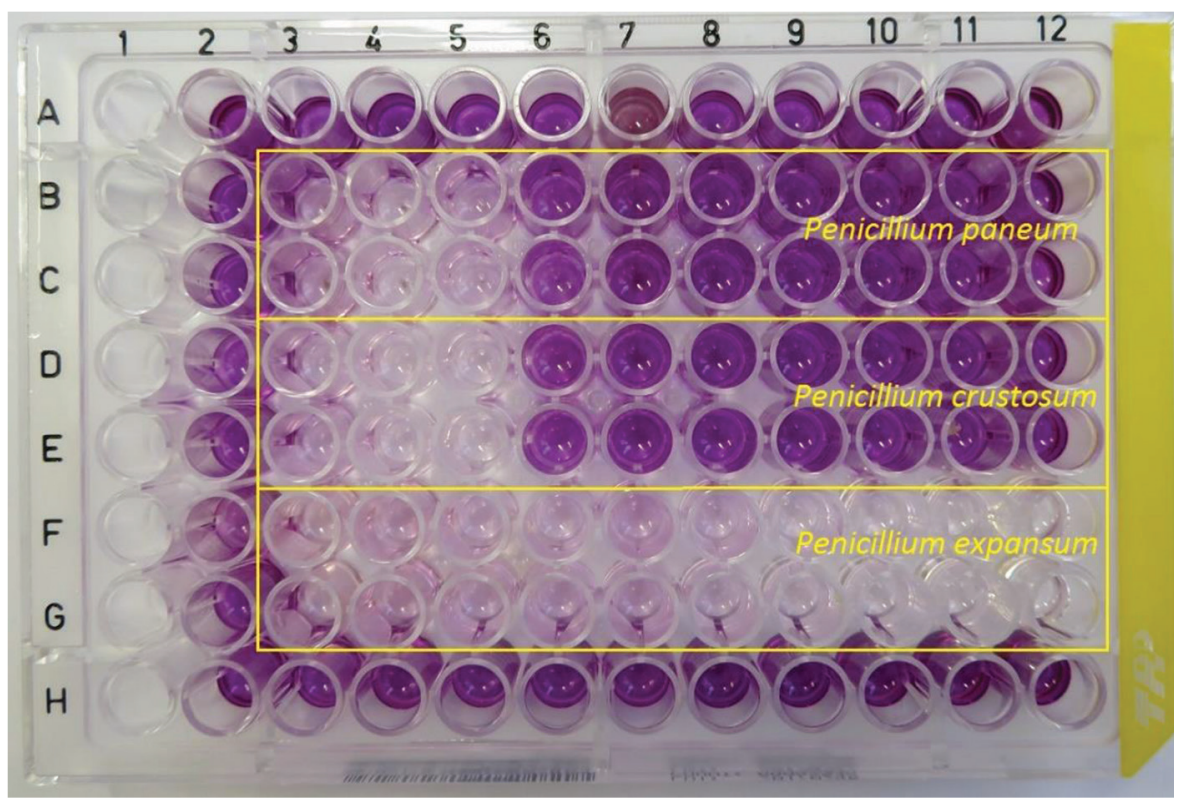

Figure 2. MTT plate for the most frequent fungal species found in mouldy acorns

\section{Mycotoxicological analysis}

Among the determined mycotoxins, mycophenolic acid and patulin were present at the highest concentrations (Table 3). In mouldy acorns, the mycophenolic acid was detected at $14580 \mu \mathrm{g} / \mathrm{kg}$ and patulin at $50 \mu \mathrm{g} / \mathrm{kg}$. In this sample, zearalenone, monoacetoxyscirpenol, diacetoxyscirpenol, T2 toxin, and ochratoxin A were detected at low levels. In the visually mould-free sample, mycophenolic acid was detected at $85.4 \mu \mathrm{g} / \mathrm{kg}$. Many toxins were not found in any of the analysed acorn samples: AFM1, AFB1, AFB2, AFG1, AFG2, 3-ADON, HT-2, DON-3-G, FUSX, $\alpha$-ZAL, $\beta$-ZAL, $\alpha$-ZOL, $\beta$-ZOL, T2 tetraol, T2 triol, NEO, $15-A D O N$, NIV, DOM-1, FB1, FB2, FB3, ROQ C, GRIS, OTB, MEV (abbreviations explained in Table 3). 
Table 3. Results of mycotoxin detection, with limits of detection (LOD) and limits of quantification (LOQ)

\begin{tabular}{|c|c|c|c|c|}
\hline Mycotoxins & $\begin{array}{c}\text { Mould-free acorns } \\
(\mu \mathrm{g} / \mathrm{kg})\end{array}$ & $\begin{array}{l}\text { Mouldy acorns } \\
(\mu \mathrm{g} / \mathrm{kg})\end{array}$ & $\begin{array}{c}\mathrm{LOD} \\
(\mu \mathrm{g} / \mathrm{kg})\end{array}$ & $\begin{array}{c}\text { LOQ } \\
(\mu \mathrm{g} / \mathrm{kg})\end{array}$ \\
\hline 15-Acetyldeoxynivalenol (15-ADON) & nd & nd & 0.8 & 2.7 \\
\hline 3-Acetyldeoxynivalenol (3-ADON) & nd & nd & 0.8 & 2.7 \\
\hline Aflatoxin B1 (AFB1) & nd & nd & 0.1 & 0.2 \\
\hline Aflatoxin B2 (AFB2) & nd & nd & 0.1 & 0.2 \\
\hline Aflatoxin G1 (AFG1) & nd & nd & 0.1 & 0.1 \\
\hline Aflatoxin G2 (AFG2) & nd & nd & 0.1 & 0.4 \\
\hline Aflatoxin M1 (AFM1) & nd & nd & 0.1 & 0.2 \\
\hline Deepoxydeoxynivalenol (DOM-1) & nd & nd & 4.2 & 14.0 \\
\hline Deoxynivalenol (DON) & nd & nd & 2.7 & 9.0 \\
\hline Deoxynivalenol-3-glucoside (DON-3-G) & nd & nd & 5.4 & 18.0 \\
\hline Diacetoxyscirpenol (DAS) & nd & $<$ LOQ & 0.3 & 1.0 \\
\hline Fumonisin B1 (FB1) & nd & nd & 0.5 & 1.7 \\
\hline Fumonisin B2 (FB2) & nd & nd & 0.4 & 1.2 \\
\hline Fumonisin B3 (FB3) & nd & nd & 0.5 & 1.5 \\
\hline Fusarenon-X (FUSX) & nd & nd & 4.8 & 16.0 \\
\hline Griseofulvin (GRIS) & nd & nd & 0.1 & 0.3 \\
\hline HT-2 Toxin (HT2) & nd & nd & 0.3 & 0.9 \\
\hline Mevinolin (MEV) & nd & nd & 0.1 & 0.3 \\
\hline Monoacetoxyscirpenol (MAS) & nd & 1.3 & 0.1 & 0.4 \\
\hline Mycophenolic acid (MPA) & 85.4 & 14580 & 0.2 & 0.7 \\
\hline Neosolaniol (NEO) & nd & nd & 0.1 & 0.3 \\
\hline Nivalenol (NIV) & nd & nd & 4.5 & 15.0 \\
\hline Ochratoxin A (OTA) & nd & 0.22 & 0.1 & 0.2 \\
\hline Ochratoxin B (OTB) & nd & nd & 0.1 & 0.3 \\
\hline Patulin (PAT) & nd & 50.0 & 1.1 & 3.5 \\
\hline Roquefortine C (ROQ C) & nd & nd & 0.2 & 0.7 \\
\hline $\mathrm{T}-2$ Toxin (T2) & nd & 0.7 & 0.1 & 0.4 \\
\hline T-2 Tetraol (T2 tetraol) & nd & nd & 5.4 & 18.0 \\
\hline T-2 Triol (T2 triol) & nd & nd & 0.3 & 1.1 \\
\hline Zearalanone (ZAN) & nd & nd & 0.5 & 1.5 \\
\hline Zearalenone (ZEN) & nd & 4.9 & 0.2 & 0.6 \\
\hline$\alpha$-Zearalanol $(\alpha-Z$ AL $)$ & nd & nd & 2.0 & 6.6 \\
\hline$\alpha$-Zearalenol $(\alpha-Z O L)$ & nd & nd & 1.0 & 3.4 \\
\hline$\beta$-Zearalanol ( $\beta$-ZAL) & nd & nd & 1.0 & 3.1 \\
\hline$\beta$-Zearalenol ( $\beta$-ZOL) & nd & nd & 1.4 & 4.8 \\
\hline
\end{tabular}

nd - not detected. 


\section{Discussion}

Toxic properties of acorns have been studied for decades (Clarke and Cotchin, 1956) but little attention has been paid to metabolites of pathogenic moulds. The cytotoxicity of moulds colonizing acorns during storage was not assessed before. The major problems usually include a lack of suitable internal standards and absent or fragmentary optimization and validation of methods. Currently, analytical techniques based on spectroscopic methods, with measurements of the ratio of mass to the electric charge of the given ion, through mass spectrum imaging, make it possible to identify secondary metabolites (mycotoxins and their derivatives) in the analysed matrix. Progressing knowledge of mycotoxin toxicity improves the methods enabling complex identification of these compounds. For example, liquid chromatography-tandem mass spectrometry ensures a high level of selectivity, low detection limit, and simultaneous identification of several dozen toxins within one analysis. In this study, LC-MS/MS allowed us to assess the exposure of livestock and wild animals to mycotoxins contained in mould-free vs. mouldy acorns. There are no published reports on the toxin-forming potential of moulds colonizing acorns. Mycotoxin levels are monitored in human food and feed in many countries, but the monitoring does not include a broad range of controlled mycotoxins. In Poland, to control feed quality and safety in the food chain, an Official Feed Control Plan has been introduced, but it includes only the main 8 of about 300 known mycotoxins. Because of their high toxicity, for these compounds the European Commission set maximum levels, guidance values or indicative levels (EC, 2006, 2013; EP, 2002). Scientific literature more and more often emphasizes that for some feed materials the results of mycotoxin assays can be underestimated. This may apply also to acorns, as mycotoxins in them are biotransformed to toxic metabolites under the influence of bacteria, fungi, and plant substances. This happens if acorns lie in a wet substrate for a long time. Rychlik et al. (2014) proposed the term modified mycotoxins, which includes modified forms of mycotoxins, and some of them are identified thanks to new instrumental methods. However, the toxicity of modified mycotoxins is poorly studied and their assays are limited due to a lack of analytical standards. There is also a shortage of certified reference materials, necessary for assessment of the parameters of analytical methods. In 2014, the European Food Safety Authority (EFSA) published a scientific opinion concerning the presence of modified mycotoxins in food and feed, which recommended further research in this field (EFSA, 2014). Our research team, studying the broadest possible spectrum of toxins in acorns, used the available standards. Mouldy acorns were strongly contaminated with mycophenolic acid and patulin, which are secondary metabolites of Penicillium spp. We also detected small or trace amounts of monoacetoxyscirpenol, ochratoxin A, T-2 toxin, and zearalenone. Visually mould-free acorns contained only mycophenolic acid, at much lower concentrations.

A review of the available scientific literature indicates that mycophenolic acid is a fungal secondary metabolite and is produced by many Penicillium spp., its derivatives are commercially used as frontline immunosuppressive agents to prevent rejection of transplant organs. Mycophenolic acid is characterized by low toxicity 
in ruminants. Mohr et al. (2007) did not report any adverse effect of this toxin on animal health and biochemical blood parameters of sheep treated with $300 \mathrm{mg}$ of mycophenolic acid $(5.4 \mathrm{mg} / \mathrm{kg})$ daily for 44 days. According to Schneweis et al. (2000), mycophenolic acid is produced not only by $P$. roquefortii but also by $P$. brevidocompactum and P. stolinoferum. Under aerobic conditions, these mould species intensively produce this metabolite, especially in grass and maize silage. The cited authors reported that in their research, mycophenolic acid did not show neurotoxic, hepatotoxic, and nephrotoxic effects. They observed some symptoms of lower resistance of the organism, so it is necessary to monitor the animals that consume large amounts of this toxin in silage. Puel et al. (2005) found that a fungal species, Byssochlamys nivea, can also produce mycophenolic acid, and its consumption by domesticated animals may substantially increase their susceptibility to infectious diseases. Sievers et al. (1997) noted that selective immunosuppressive activity of this acid is known, as it limits purine metabolism. Effects of mycophenolic acid in sheep were also presented by Džidić et al. (2004), but they found that its toxicity is low. Nevertheless, in silage it can accumulate, so it can be associated with increased infections in animals (Baum et al., 2005).

A new and undoubtedly interesting problem concerning mycotoxicological evaluation of acorns is the high level of patulin in mouldy acorns. Patulin is produced mainly by Penicillium and Aspergillus spp., but the most important among them is P. expansum (Weidenbörner, 2000). This toxin is most often detected in apples, apple juices, and processed products containing them. Patulin is less frequently found in other fruits, such as grapes or pears. Long-term exposure to patulin is accompanied with genotoxicity, cytotoxicity, immunotoxicity, neurotoxicity, and severe damage to mammalian organs, especially kidney and liver (Zhong et al., 2018). The permissible maximum content of this mycotoxin in juices and fruit nectars is $50 \mu \mathrm{g} / \mathrm{kg}$, while in apple products (apple compote, apple puree) intended for direct consumption, it must not exceed $25 \mu \mathrm{g} / \mathrm{kg}$ (Commission Regulation (EC) No. 1425/2003).

Patulin was first isolated in 1941 from $P$. grizeofulvum, when searching for new antibiotics. It showed antifungal and antibacterial activity (particularly against $M y$ cobacterium tuberculosum). However, it is cytotoxic (Weidenbörner, 2000). Blood (1998) signalized that swine are the most sensitive to patulin. It was assumed that patulin toxicity to livestock is low, as it is produced mostly on apples and thus can be transmitted to food products, but if consumed by pigs, it can affect the nervous system by a cellular mechanism. Its symptoms include vomiting, salivation, poor appetite, but sometimes also leucocytosis and erythropenia. In ruminants, it may cause problems with fibre digestibility and lower production of volatile fatty acids as well as synthesis of microbiological proteins.

In mouldy acorns, we detected also trace amounts of ochratoxin A, which - like patulin - is produced by storage moulds: Aspergillus and Penicillium spp. We also found low concentrations of Fusarium metabolites: T-2 toxin, zearalenone, and monoacetoxyscirpenol, which are type A and B trichothecenes, showing a broad spectrum of activity and toxic effects: from chronic contamination to acute poisoning. They influence animals primarily through the digestive system, as cytotoxic compounds. This group of mycotoxins can bind glucose and form a masked mycotoxin. 
On average, mouldy acorns contained $2.6 \times 10^{6} \mathrm{cfu} / \mathrm{g}$. Out of the 15 analysed samples of this material, $100 \%$ were contaminated with Penicillium, 12 samples with Mucor, 2 with Trichoderma, 1 with Alternaria, and 1 with Fusarium. Among Penicillium spp., 5 samples contained P. paneum (which can produce 1-octen-3ol and penipanoid A), another 5 samples contained $P$. expansum (which produces patulin), while in 3 samples, $P$. crustosum was present (which produces neurotoxic toxin penitrem A), and in 2 samples, P. aurantiogruseum (forming penicillic acid). Those secondary metabolites are toxic, often cytotoxic. In most samples, we found also moulds Mucor hiemalis or Mucor circinelloides, which produce toxins (e.g. 3-nitropropionic acid). Those species of the order Mucorales, with Rhizopus and Absidia, can cause mucormycoses, i.e. fungal diseases of humans and animals (Weidenbörner, 2000).

In mouldy acorns, toxic effects of their secondary metabolites can be combined. The resultant mycotoxins can act synergistically, and the potential combined effects of such mixtures on animal health are poorly studied. Major interactions between toxins are: additivity, synergism, and antagonism (Grenier and Oswald, 2011). It is extremely difficult to interpret research results concerning the overall toxicity of groups of mycotoxins, especially of long-term exposure to low doses of mycotoxins. That is why, apart from instrumental analyses, various cell types are used for cytotoxicity tests, or various model animals, characterized by variation between individuals (Smith et al., 2016). In research on mycotoxins and assessment of their toxicity, it is very important to select suitable methods of qualitative and quantitative analysis. However, the use of chromatographic techniques with diode array detector (DAD) detector or fluorescence detector (FLD) or LC-MS/MS, depending on the matrix, sometimes is not sufficiently effective. That is why cytotoxicity of isolated fungi is assessed. The analysed acorns were dominated by pathogenic moulds of the genus Penicillium. MTT assay was performed for 3 dominant species. For swine kidney cells, the most cytotoxic species was P. expansum $\left(\mathrm{IC}_{50} 0.061 \mathrm{~cm}^{2} / \mathrm{ml}\right)$. Such a high toxicity can be correlated with its ability to produce secondary metabolites, such as patulin, citrinin, roquefortine $\mathrm{C}$. The fungus causes blue mould, which is economically the most important disease of harvested fruits and vegetables in cold stores (Weidenbörner, 2000). The other 2 assessed species were characterized by low cytotoxicity. However, Chitarra et al. (2004) noted that $P$. paneum often contaminates cereal grain and can produce mycotoxins roquefortine $\mathrm{C}$ and patulin, which are toxic to animals and people. Our study shows that on acorns of pedunculate oak during storage some moulds develop and synthesize specific mycotoxins. Because of the common occurrence of unmodified and modified metabolites of moulds, the European Commission is currently developing amendments to existing legislation concerning mycotoxin limits in feeds for various animal species. Our data on fungal toxicity and coexistence of toxins in acorns can help in correct and precise analysis of human and animal exposure to mycotoxins. The presence of moulds and mycotoxins in food and feeds is a health risk to humans and animals. They can cause acute poisoning (relatively rare) or chronic poisoning, due to long-term consumption of low doses of the toxins. Pathogenic moulds, as a result of infection from the environment, are responsible for systemic fungal infections. Mycotoxin levels are monitored in many countries but the studies do not cover a broad range of toxins. 


\section{Conclusions}

In this study, mycotoxin levels in acorns infected with moulds and in those showing no visual symptoms of infection were determined. Visually mould-free acorns contained only mycophenolic acid in a slight amount $(85.4 \mu \mathrm{g} / \mathrm{kg})$. In contrast, mouldy acorns contained a high level of mycophenolic acid $(14580 \mu \mathrm{g} / \mathrm{kg})$, patulin $(50 \mu \mathrm{g} / \mathrm{kg})$ and zearalenone $(4.9 \mu \mathrm{g} / \mathrm{kg})$. Additionally, trace amounts of monoacetoxyscirpenol, ochratoxin A, and T-2 toxin were detected. Among the detected toxins, especially patulin is subject to strict regulations as regards its toxicity as well as the teratogenic and carcinogenic effect. We did not detect any mycotoxins that potentially pose a serious threat to consumers of food products originated from animals fed with acorns, e.g. aflatoxin B1, while ochratoxin A was detected but at a very low level. In visually mould-free acorns, the average number of fungi (cfu/g) was about $1 \times 10^{4}$, compared to $2.6 \times 10^{6}$ in mouldy ones. The dominant mould species were: Penicillium expansum, P. paneum, P. crustosum, P. aurantiogriseum, Mucor hiemalis, and M. circinelloides.

The popularity of acorn products as a "super food" for humans and as a special feed additive for pigs improving meat quality, is growing nowadays. Our results confirmed that it is justified to discuss the possibility of acorn contamination with moulds and mycotoxins, as this feed material is commonly stored several months, from autumn till spring. The possibility of co-occurrence of several mycotoxins must be taken into account as in livestock and people consuming acorns they can cause chronic exposure.

\section{References}

B aum B., Mohr A., Pfaffl M., Bauer J., Hewi cker-Trautwe in M. (2005). Morphological findings in lymphatic tissues of sheep following oral application of the immunosuppressive mycotoxin mycophenolic acid. Mycopathologia, 160: 167-175.

B l o o d D. (1998). Poradnik lekarza weterynarii (Pocket companion to veterinary medicine) (in Polish). PZWL, 1st ed. Warszawa, Poland.

Charef M., Mohamed Y., S a id i M., S t o c ker P. (2008). Determination of the fatty acid composition of acorn (Quercus), Pistacia lentiscus seeds growing in Algeria. J. Am. Oil Chem. Soc., 85: $921-924$.

Chitarra G.S., Abee T., Rombouts F.M., Posthumus M.A., Dijksterhuis J. (2004). Germination of Penicillium paneum conidia is regulated by 1-octen-3-ol, a volatile self-inhibitor. Appl. Environ. Microbiol., 70: 2823-2829.

Clarke E.G.C., C ot c h in E. (1956). A note on the toxicity of the acorn. Brit. Vet. J., 112: 135-139.

Commission Regulation (EC) No 1425/2003 of 11 August 2003 amending Regulation (EC) No 466/2001 as regards patulin (Text with EEA relevance). Off. J. Eur. Union, L203: 1-3.

D ing e r m a n n T., Kr e is W., R i m p le r H., Z ün d or f I. (2012). Biologia Farmaceutyczna, Reinhard E. (ed.) (in Polish). MedPharm, Wrocław, Poland.

DLG-Futterwerttabellen für Wiederkäuer (1982). 5. erweit. u. neu gestalt Auflage. DLG-Verlag, Frankfurt am Main.

Dži dić A., M ohr A., M e y e r K., B a u e r J., M e yer H.H.D., P fa ffl M.W. (2004). Effects of mycophenolic acid (MPA) treatment on expression of Fc receptor (FcRn) and polymeric immunoglobulin receptor (pIgR) mRNA in adult sheep tissues. Croat. Med. J., 45: 130-135.

European Commission (EC) (2006). Commission Recommendation 2006/576/EC of 17 August 2006 on the presence of deoxynivalenol, zearalenone, ochratoxin A, T-2 and HT-2 and fumonisins in products intended for animal feeding. Off. J. Eur. Union., L229: 7-9. 
European Commission (EC) (2013). Commission Recommendation 2013/165/EC of 27 March on the presence of T-2 and HT-2 toxin in cereals and cereal products. Off. J. Eur. Union., L91: 12-15.

European Food Safety Authority (EFSA). (2014). Scientific Opinion on the risks for human and animal health related to the presence of modified forms of certain mycotoxins in food and feed. EFSA J., 12: 3916.

European Parliament (EP) and the Council of the EU (2002). Directive of the European Parliament and of the Council of 7 May 2002 on undesirable substances in animal feed. Off. J. Eur. Communities, L0032: 1-15.

F a s s a ti o vá O. (1983). Grzyby mikroskopowe w mikrobiologii technicznej (in Polish). Wyd. Nauk. Techn., Warszawa, Poland, 255 pp.

F e e d i n a m i c s (2020). INRAE-CIRAD-AFZ Feed tables. Available online: https://www.feedtables. com/content/feeds (accessed on 1.12.2020).

F r i s v a ld J.C., S a m s o n R.A. (1991). Filamentous fungi in foods and feeds: ecology, spoilage, and mycotoxin production. In: Handbook of applied mycology, Arora D.K., Mukerji K.G., Marth E.H. (eds). Vol. 3. Foods and feeds. Marcel Dekker, New York, pp. 31-68.

Grenier B., Oswald I. (2011). Mycotoxin co-contamination of food and feed: meta-analysis of publications describing toxicological interactions. World Mycotoxin J., 4: 285-313.

Hanelt M., Gare is M., Kollarczik B. (1994). Cytotoxicity of mycotoxins evaluated by the MTT-cell culture assay. Mycopathologia, 128: 167-174.

J i a n g F., D u s t in g G.J. (2003). Natural phenolic compounds as cardiovascular therapeutic: potential role of their antiinflammatory effects. Curr Vasc Pharmacol, 1: 135-56.

Kamphues J., C o en en M., K i enzle E., P a 11 a u f J., S i m on O., Z e n te k J. (2004). Supplemente zu Vorlesungen und Übungen in der Tierernährung. Verlag M.\&H. Schaper Alfeld-Hannover, Germany.

K or u s J., Witc zak M., Z i o bro R., J u s z c zak L. (2015). The influence of acorn flour on rheological properties of gluten free dough and physical characteristics of the bread. Eur. Food Res. Technol., 6: 1135-1143.

K o zło w s k a C. (1970). Investigations on fungi occuring on oak and birch fruits and on pine and larch seeds (in Polish). Pr. Inst. Bad. Leś., 386: 1-120.

Krah l- Urban J. (1959). Die Eichen. Forstliche Monographie der Traubeneiche und der Stieleiche. Paul Parey Hamburg/ Berlin, Germany.

L e e K.W., Hur H.J., L e e H.J., L e e C.Y. (2005). Antiproliferative effects of dietary phenolic substances and hydrogen peroxide. J. Agric. Food Chem., 53: 1990-1995.

M án k a K. (1998). Fitopatologia Leśna (in Polish). PWRiL, 5th ed., Warszawa, Poland.

Mohr A.I., L orenz I., B a um B., H ew i cker-Trautwe in M., P faffl M.W., Džidić A., Meye r H.H.D., B a u e r J., M e yer K. (2007). Influence of oral application of mycophenolic acid on the clinical health status of sheep. J. Vet. Med. A., 54: 76-81.

Ortiz A., Carrillo N., Elghann a A., Es criban o M., Gas par P. (2020). Views of farmers and industrial entrepreneurs on the Iberian pig quality standard: an in-depth interview research study. Animals (Basel), 10: 1772.

Ö z c a n T. (2007). Characterization of Turkish Quercus L. taxa based on fatty acid compositions of the acorns. J. Am. Oil Chem. Soc., 84: 653-662.

Pignone D., La ghett i G. (2010) On sweet acorn (Quercus spp.) cake tradition in Italian cultural and ethnic islands. Genet. Resour. Crop Evol., 57: 1261-1266.

P i t t J.I. (2000). A laboratory guide to common Penicillium species. Food Sci. Aus., 197 pp.

P it t J.I., H o cking A.D. (1999). Fungi and Food Spoilage. Gaithersburg: Aspen Publication, 2nd ed., $593 \mathrm{pp}$.

Przy był K. (1999). Diseased changes in roots dead and showing decay. Zesz. Nauk. AR, Kraków, 348: $143-152$.

Przybył K. (2006). More important infectious diseases. In: Dęby, Bugała W. (ed.). PAN, Kurnik, P o land, pp. 742-772.

Puel O., Tadrist S., Galt i e r P., O s w ald I.P., D e 1 a f o r g e M. (2005). Byssochlamys nivea as a source of mycophenolic acid. Appl. Environ. Microbiol., 71: 550-553.

Rabhi F., Narváez-Rivas M., Tlili N., B oukhchina S., León-Ca ma cho M. (2016). Sterol, aliphatic alcohol and tocopherol contents of Quercus ilex and Quercus suber from different regions. Ind. Crop. Prod., 83: 781-786. 
Rakić S., Povrenović D., Tešević V., S imić M., Maletića R. (2006). Oak acorn, polyphenols and antioxidant activity in functional food. J. Food Eng., 74: 416-423.

Rychlik M., Humpf H.U., Marko D., Dänicke S., Mally A., Berthiller F., Klaffke H., L or en z N. (2014). Proposal of a comprehensive definition of modified and other forms of mycotoxins including "masked" mycotoxins. Mycotoxin Res., 30: 197-205.

S a m s o n R.A., F r i s v a ld J.C. (2004). Penicillium subgenus Penicillium: new taxonomic schemes, mycotoxins and other extrolites. Stud. Mycol., 49: 1-260.

S a m son R.A., Houbraken J., Thrane U., Frisvad J.C., Andersen B. (2010). Food and indoor fungi. CBS-KNAW Fungal Biodiversity Centre, 2nd ed., 390 pp.

S chneweis I., Meyer K., Hormansdorfer S., B a uer J. (2000). Mycophenolic acid in silage. App. Environ. Microbiol., 66: 3639-3641.

S chröder T., van Hörsten D., Kehr R. (1999). Thermotherapie von Traubeneicheln mit Mikrowellenenergie. Mitt. Biol. Bundesanst. Land-Forstwirtsch. Berlin-Dahlem, 365: 23-38.

S i evers T.M., Rossi S.J. Ghobrial R.M., Arriola E., Nishimura P., Kaw ano M.K., H o lt C.D. (1997). Mycophenoloate Mofetil. Pharmacotherapy, 17: 1178-1197.

S mith M.C., M a d e c S., C o t o n E., H y m e ry N. (2016). Natural co-occurrence of mycotoxins in foods and feeds and their in vitro combined toxicological effects. Toxins (Basel), 8: 94.

U 11 a h M.F., K h a n M.W. (2008). Food as medicine: Potential therapeutic tendencies of plant derived polyphenolic compounds. Asian Pac. J. Cancer Prev., 9: 187-196.

Viegas C., Faria T., Aranha Caetano L., Carolino E., Quintal-Gomes A., Tw a r uż e k M., K o s i c k i R., Vi e g a s S. (2019). Characterization of occupational exposure to fungal burden in Portuguese bakeries. Microorganisms, 7: 234.

We id e n börner M. (2000). Lexikon der Lebensmittelmykologie. Springer-Verlag, Berlin Heidelberg.

Z ho ng L., C are re J., L u Z., L u F., Z h o u T. (2018). Patulin in apples and apple-based food products: the burdens and the mitigation strategies. Toxins, 10: 475 .

Received: 25 IX 2020

Accepted: 9 III 2021 